\title{
The In vitro Effects of Atenolol and Zinc Chloride on the Protein Binding of Amlodipine in Aqueous Medium
}

\author{
Md. Shah Amran ${ }^{1}$, Sheikh Niaz Morshed ${ }^{2}$, Md. J ahangir Alam Khandakar ${ }^{2}$, \\ Md. Masudur Rahman ${ }^{2}$, Md. Mosiur Rahman ${ }^{2}$ and Md. Amj ad Hossain ${ }^{1}$ \\ ${ }^{1}$ Department of Pharmaceutical Chemistry, Faculty of Pharmacy, University of Dhaka, Dhaka 1000, Bangladesh \\ ${ }^{2}$ Department of Pharmacy, Faculty of Science, Rajshahi University, Rajshahi 6205, Bangladesh.
}

\begin{abstract}
An in vitro study of protein binding has been carried out to observe the influence of atenolol and zinc chloride on the protein binding of amlodipine by equilibrium dialysis method at $37 \pm 1{ }^{\circ} \mathrm{C}$ and at physiological $\mathrm{pH}$ (7.4). It has been found that zinc chloride lowered the affinity and percentage of protein binding of amlodipine to bovine serum albumin but atenolol has no such effect. The Scatchard plots were prepared to reveal the number of binding sites and the affinity for protein binding. It was seen that the highest percentage binding of amlodipine was $91 \%$ and the lowest was $74 \%$. In the presence of atenolol, the highest and the lowest value of percentage of protein binding was $90 \%$ and $72 \%$, respectively. In the presence of zinc chloride these values were $84 \%$ and $65 \%$ respectively. It is, thus, inferred that atenolol or its complex with amlodipine has no significant effect on percentage of protein binding of amlodipine. While zinc chloride or its complex with amlodipine can cause a decrease in percentage of protein binding of amlodipine. Complexation of amlodipine with zinc chloride might, therefore, displace the drug from the plasma and the displaced drugs may be redistributed, thus, increasing the free drug in plasma and tissue systems. This may change the pharmacokinetic properties of the drug and may affect the pharmacological and toxic effects. It is thus inferred that care and monitoring must be taken during combination therapy of amlodipine and zinc chloride.
\end{abstract}

Key words: Amlodipine, protein binding, binding site, equilibrium dialysis, Scatchard plot, atenolol, zinc chloride, combination therapy

\section{INTRODUCTION}

Amlodipine is an important calcium channel blocker which has gained wide acceptance in the treatment of various types of cardiovascular diseases such as angina pectoris, hypertension and cardiac arrhythmias. ${ }^{1,2}$ Atenolol is a beta blocker and used in the indications same as amlodipine. Zinc chloride is an important metal ion indicated for growth retardation, diarrhea, respirtory tract infection (RTI), congenital malformations, mental disturbances, dermatitis, immunological disturbances etc. ${ }^{3,4}$ The chemical structures of all these agents are given in Figure 1.

Correspondence author: Md. Shah Amran

Tel: +88-721-750041-4110, Fax: +88-721-750064,

E-mail: amdshah@yahoo.com

Dhaka Univ. J. Pharm. Sci. 7(1): 15-21, 2008 (June)
Plasma protein binding is one of the important and useful pharmacokinetic parameters of a drug. There are multiple binding sites on a protein molecule. The pharmacokinetic and pharmacodynamic behavior of a drug are governed by the strength of a complex formed with the protein. Drugs generally form reversible complexes with the plasma proteins that act as a reservior releasing the free drug to the circulation. Free form (of the drug) shows pharmacologic response, is metabolized and excreted. Bound (to the plasma protein) drug is gradually released to maintain the equilibrium and thus the pharmacologic response is maintained. The type and nature of protein binding depend on the physicochemical properties of the drug molecules, 
<smiles>CCOC(=O)C1=C(COCCN)NC(C)=C(C(=O)OC)C1c1ccccc1Cl</smiles>

Amlodipine

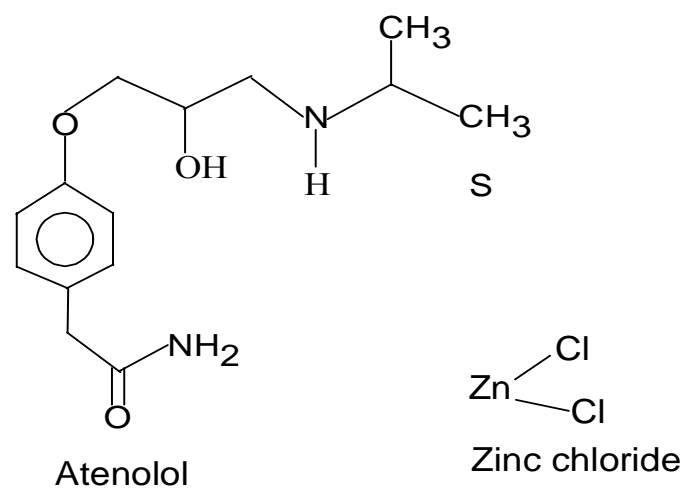

Figure 1. The chemical structures of amlodipine, atenolol and zinc chloride

their concentration, $\mathrm{pH}$ of the medium and also on the concentration and number of available binding sites of the plasma proteins. Protein binding of a drug is a limiting factor for drug effect. Simultaneous administration of two or more drugs into the systemic circulation can modify the affinity of the drug to bind with plasma protein and thus percentage of protein binding. Due to this modification, the combined therapy can change the volume of distribution, renal and hepatic clearance, and hence drug effect. ${ }^{5,6}$ This study was aimed to evaluate the influence of atenolol and zinc chloride on the percentage of protein binding at physiological conditions $(\mathrm{pH} 7.4$ and temperature $37 \pm 1^{\circ} \mathrm{C}$ ) and thus to infer about the combination therapy. To the best of our knowledge, there was no report on the study of effect of protein binding between amlodipine and atenolol and zinc chloride. The present study, therefore, was aimed to explore the effect of protein binding of atenolol and zinc chloride on amlodipine.

\section{MATERIALS AND METHODS}

Drugs and Chemicals. Amlodipine hydrochloride and atenolol were kind gifts from Chemico Pharmaceutical Ltd., Rajshahi, Bangladesh. Bovine serum albumin (Fraction V, 96-98\%, Sigma) and semipermeable membrane (Medicell, England) and all other reagents were purchased from BDH (England). Phosphate buffers were prepared following standard methods. ${ }^{7,8}$

Apparatus. A digital $\mathrm{pH}$ meter (Jenway, London) was used to adjust the $\mathrm{pH}$ of the buffer solutions. A recording UV/VIS spectrophotometer (UV-160, Shimadzu, Japan) was used for the measurement of absorbance of the unbound drugs present in the buffer compartment. A Dunbuff metabolic shaking incubator (GCA corporation, USA) was used to shake the plasma-drug mixtures for the attainment of equilibrium.

Equilibrium dialysis. In this experiment, the membranes were activated by digestion with $1.0 \mathrm{M}$ sodium bicarbonate at $70^{\circ} \mathrm{C}$ for four hours and washing thoroughly with deionized water and immersing in $1 / 15 \mathrm{M}$ (or, $0.067 \mathrm{M}$ ) phosphate buffer of $\mathrm{pH}$ 7.4. Activated membrane bags $(12 \mathrm{~cm}$ long, 3.0 $\mathrm{ml}$ capacity) were filled with solutions of serum bovine albumin with different concentration of the drugs and their mixtures. The membrane bags were immersed in a fixed amount $(50 \mathrm{ml})$ of phosphate buffer and the system was shaken gently for six hours in a metabolic shaking incubator at $37 \pm 1^{\circ} \mathrm{C}$. After completion of dialysis the absorbance of the buffer (outside the membrane bags) was measured at 240 $\mathrm{nm}$ and the concentrations of the bound and unbound drugs were found using a standard curve.

Determination of the Lamda max $\left(\lambda_{\max }\right)$ for amlodipine to be used in this work. A stock solution of amlodipine was prepared in small volume of methanol and then working solutions were prepared by diluting with water in all cases. Thus, the aqueous solutions of different concentrations of amlodipine (as Active Pharmaceutical Iingredient, not as marketted product) $(20-100 \mu \mathrm{M})$ were prepared and their absorbance was measured to findout the $\lambda_{\max }$ of amlodipine (Figure 2a-c and d) and it was 
observed that for amlodipine maximum absorption was occurred at $240 \mathrm{~nm}$ in aqueous sulution and the subsequent work was performed using this value as the $\lambda_{\max }$ for amlodipine, although BP suggests $360 \mathrm{~nm}$ as $\lambda_{\max }$ for marketted product of amlodipine in acidic solution. $^{9}$

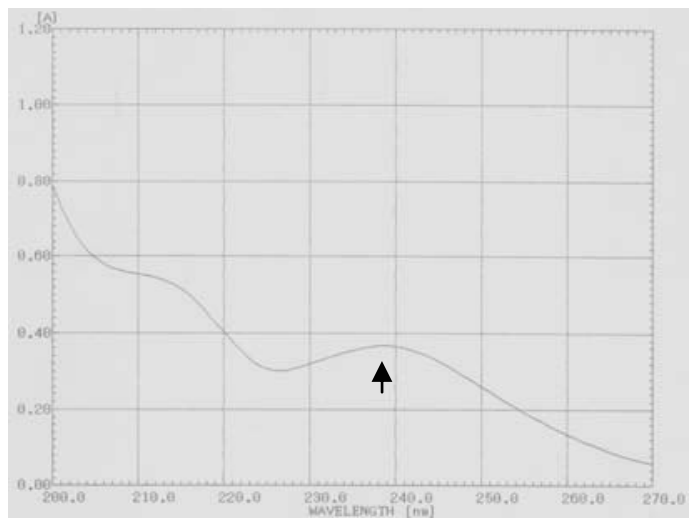

(a)

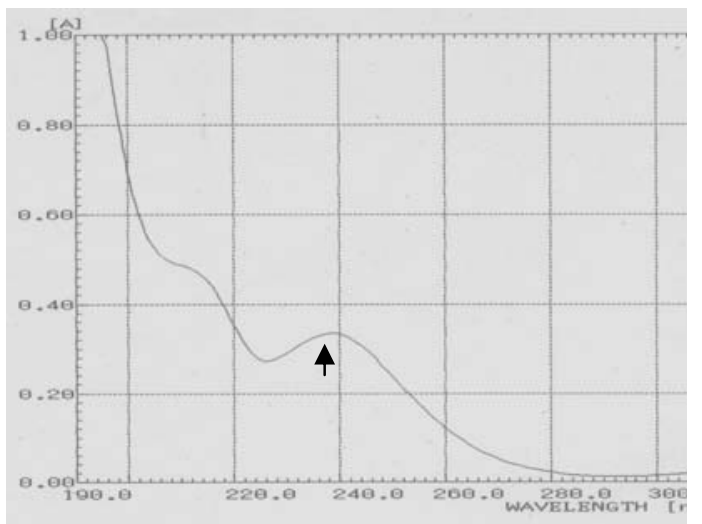

(c)
Preparation of standard curve. A standard curve was used for the spectrophotometric determination of concentration of drugs in the buffer chamber. A treated buffer was used for this purpose. This buffer was obtained by allowing the equilibrium dialysis of the permeable fragments of free plasma from the inside of the membrane bags to the buffer solution ( $0.067 \mathrm{M}$ phosphate, $\mathrm{pH}$ 7.4.).

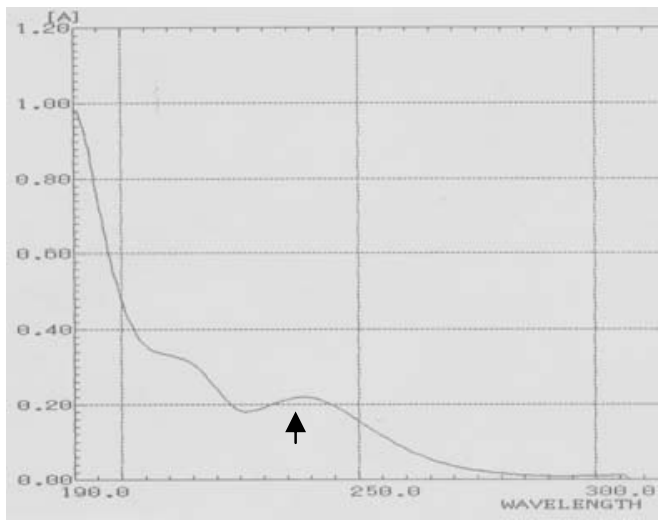

(b)

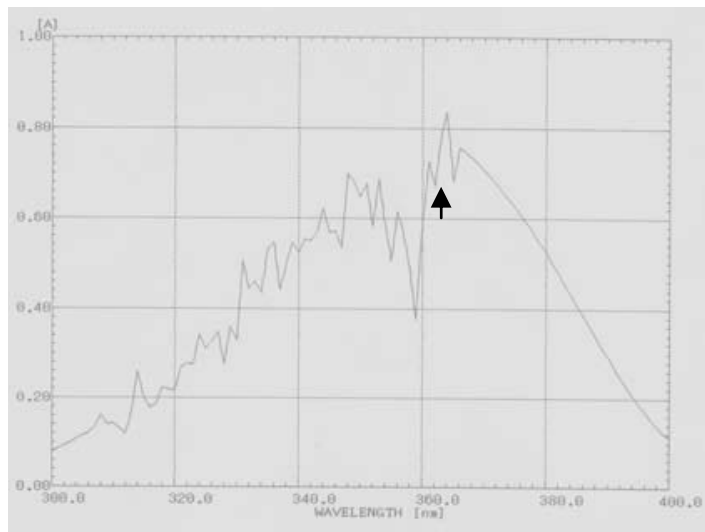

(d)

Figure 2. Screening for maximum absorption $\left(\lambda_{\max }\right)$ for amlodipine in aqueous medium and according to British Pharmacopea method. Arrows indicate the $\lambda_{\max }$ at $240 \mathrm{~nm}$ from (a)-(c) at concentrations $20-100 \mu \mathrm{M}$ and blank triangle indicates the $\lambda_{\max }$ at $360 \mathrm{~nm}$ according to BP method. The range of wavelength used to measure the absorbance of amlodipine from (a to c) are (a) 190-270 nm, (b) 190-300 $\mathrm{nm}$, (c) $190-400 \mathrm{~nm}$, and the wavelength of amlodipine as per BP is $360 \mathrm{~nm}$ and the range used is (d) $300-400 \mathrm{~nm}$

Then the solution of different concentration of amlodipine were prepared in this buffer and their absorbance was measured at $240 \mathrm{~nm}$ which is the $\lambda_{\max }$ of amlodipine. A standard curve was made by plotting absorbance against the concentration of amlodipine (Figure 3).
Calculation of percentage of protein binding. The percentage of protein binding $(\mathrm{F})$ is given by

$$
\mathrm{F}=\frac{\mathrm{B}-\mathrm{A}}{\mathrm{B}} \times 100
$$

Where, $\mathrm{A}=$ Molar concentration of free drug in buffer compartment

$\mathrm{B}=$ Molar concentration of total drug in protein compartment 


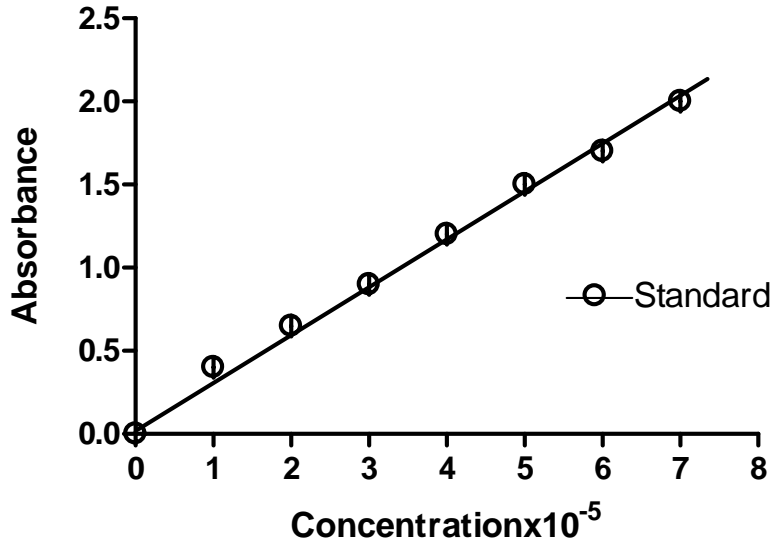

Figure 3. The standard curve of amlodipine for equilibrium dialysis method. The data are shown as mean \pm SEM

Calculation of affinity constants and number of binding sites. The Scatchard method ${ }^{6,10,11}$ was used for this purpose and a curve was thus produced by plotting ' $\mathrm{r} /[\mathrm{A}]$ ' versus ' $\mathrm{r}$ ' using the equation

$$
\mathrm{r}=\frac{[\mathrm{B}]-[\mathrm{A}]}{[\text { Protein }]}
$$

where, $r=$ the ratio between the molar concentration of the bound drug and the molar concentration of protein. The curve so obtained when extrapolated gave an intercept on the $\mathrm{Y}$ axis representing $\mathrm{nKa}$, the intersection on the $\mathrm{X}$-axis representing $\mathrm{n}$ and the slope of the line being $\mathrm{Ka}$, where, $\mathrm{n}=$ the number of binding sites on the protein available to bind drug molecule or its complex, $\mathrm{Ka}=$ affinity constant (or, binding force) for the binding of drug or its complex.

Statistics. Data were presented as mean \pm S.E.M. Differences in mean values between experimental data were analyzed, where necessary, by unpaired ' $t$ ' test. A probability value of 0.05 $(p<0.05)$ was defined to be significant. Data were analyzed by the software graphpadPrism.

\section{RESULTS AND DISCUSSION}

The invitro determination of percentage of protein binding of amlodipine and its $1: 1$ mixtures of atenolol and zinc chloride has been conducted at room temperature and $\mathrm{pH}$ 7.4. The highest percentage of amlodipine binding with bovine serum albumin was found to be $90 \%$. The percentage of protein binding of amlodipine has been found to increase with increase of the concentration of amlodipine which attained a steady plateau state when the free amlodipine concentration was around $5 \times 10^{-5} \mathrm{M}$. This might be the saturation zone for the protein binding of amlodipine (Figure 4a). It was observed that, atenolol did not affect the protein binding profile of amlodipine (Mean \pm SEM, ns, not significant because $\mathrm{p}=0.7868$ ) (Figure 4b). This might be due to formation of highly reversible complexes between amlodipine and atenolol. On the otherhand, zinc chloride was found to significantly decrease (mean \pm SEM, *significant because $\mathrm{p}=0.0454$ ) the percentage of protein binding of amlodipine at the concentration range used but the attainment of steady plateau condition remained unchanged (Figure 4c).

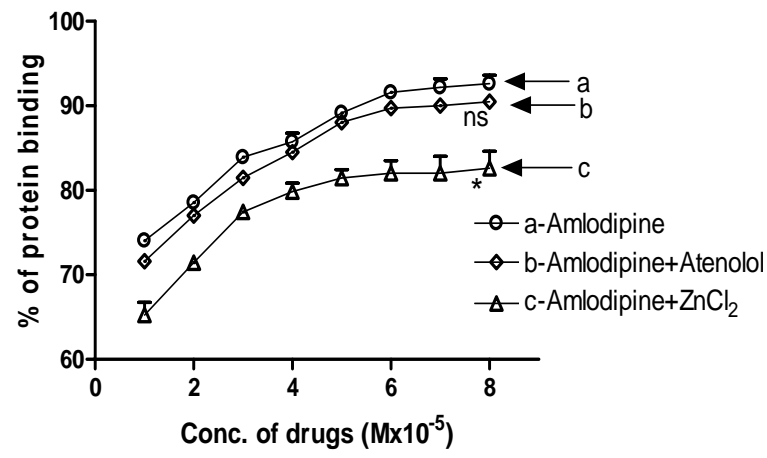

Figure 4. The protein binding of amlodipine, amlodipine-atenolol and amlodipine zinc chloride systems at $\mathrm{pH} 7.4$ and temperature $37 \pm 1^{\circ} \mathrm{C}$. The data are shown as mean $\pm \mathrm{SEM}$. *indicates significant change $(\mathrm{p}=0.0454)$ in preotein binding by zinc chloride with respect to amlodipine

In otherwords, the complex formation of zinc chloride with amlodipine can increase unbound fraction in plasma at high concentrations. This might alter the therapeutic response, toxic effects and pharmacologic properties of amlodipine. These findings are similar to our previous findings. ${ }^{12,13}$ It was also observed that all forms of the drugs (amlodipine and its 1:1 mixtures with atenolol and zinc chloride) attained a steady plateau condition at higher concentrations. This indicated the saturation of the sites of protein by the drugs or its complexes as was observed by other investigators. ${ }^{14-16}$ The 
concentration of drugs or the drug mixture were kept within $1 \times 10^{-5} \mathrm{M}$ to $8 \times 10^{-5} \mathrm{M}$, while that of bovine serum albumin was kept at $5 \times 10^{-5} \mathrm{M}$ so that the protein binding sites were sufficient to bind all the drug molecules. It was found that nearly mole to mole binding occurred because the values of percentage of protein binding at concentration $5 \times$ $10^{-5} \mathrm{M}$ were $89 \%, 88 \%$ and $82 \%$ for amlodipine alone, amlodipine-atenolol and amlodipine-zinc chloride systems, respectively. At this point the binding phenomenon reached nearly maximum values what is called saturation zone of binding. At low concentrations $\left(1 \times 10^{-5}\right.$ to $\left.5 \times 10^{-5} \mathrm{M}\right)$ the percentage of protein binding increased almost linearly and at high concentrations $\left(6 \times 10^{-5}\right.$ to $8 \times$ $\left.10^{-5} \mathrm{M}\right)$ the percentage of protein binding did not increase sharply. It can therefore be inferred that complexation of amlodipine with the drugs being studied can displace the drug from the plasma. Since the drug displaced from the plasma protein will redistribute into its full potential volume of distribution, the concentration of free drug in plasma and tissues after redistribution might be increased greatly and this might change the pharmacokinetic propeties of the drug and thereby may affect its pharmacologic and toxic effects. ${ }^{12}$ Care and monitoring should, therefore, be exercised during combination therapy with such drugs, specially zinc chloride.

It was found that there are al least two binding sites for amlodipine and its complexes with atenolol and zinc chloride (Figure 5 to Figure 7, and Table 1).

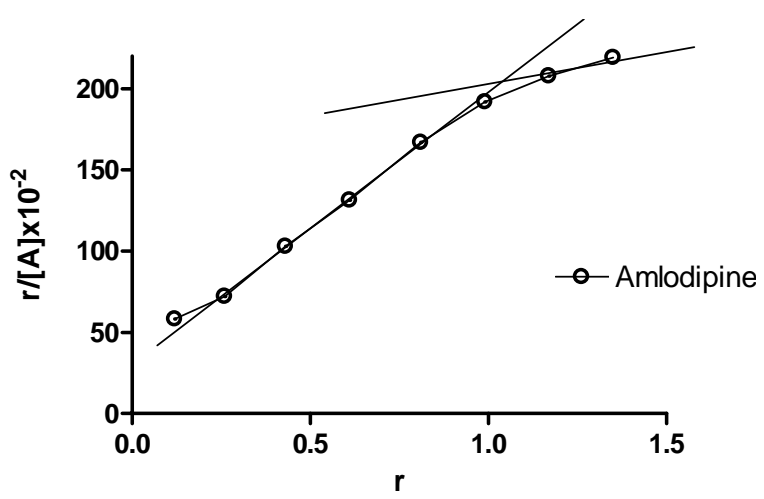

Figure 5. The Scatchard plot for protein binding capacity of amlodipine alone. The data are shown as mean \pm SEM
The number of binding sites $\left(\mathrm{n}_{1}\right)$ in class I was found to be 1.26, 1.14 and 1.28 for amlodipine, amlodipine-atenolol and amlodipine-zinc chloride systems, respectively. The values of affinity constants $\left(\mathrm{K}_{1}\right)$ with these class of sites have been found to be $107.5,95.9$ and 68.8 , respectively.

Table 1. The number of protein binding sites and the associated affinity constants of amlodipine and its $1: 1$ mixtures with atenolol and zinc chloride systems

\begin{tabular}{lcccccc}
\hline \multirow{2}{*}{ Systems } & \multicolumn{3}{c}{ Class I binding sites } & \multicolumn{3}{c}{ Class II binding sites } \\
\cline { 2 - 7 } & $\mathrm{N}_{1} \mathrm{k}_{1}$ & $\mathrm{~K}_{1}$ & $\mathrm{~N}_{1}$ & $\mathrm{~N}_{2} \mathrm{k}_{2}$ & $\mathrm{~K}_{2}$ & $\mathrm{~N}_{2}$ \\
\hline Amlodipine & 107.5 & 85 & 1.26 & 29 & 180 & 0.16 \\
$\begin{array}{l}\text { Amlodipine+ } \\
\text { Atenolol }\end{array}$ & 95.89 & 84.21 & 1.14 & 26 & 176 & 0.15 \\
$\begin{array}{l}\text { Amlodipine+ } \\
\text { Zinc chloride }\end{array}$ & 68.66 & 53.33 & 1.28 & 21 & 130 & 0.16 \\
\hline
\end{tabular}

The number of binding sites $\left(\mathrm{n}_{2}\right)$ in class II was found to be $0.16,0.15$ and 0.16 for amlodipine, amlodipine-atenolol and amlodipine-zinc chloride systems, respectively.

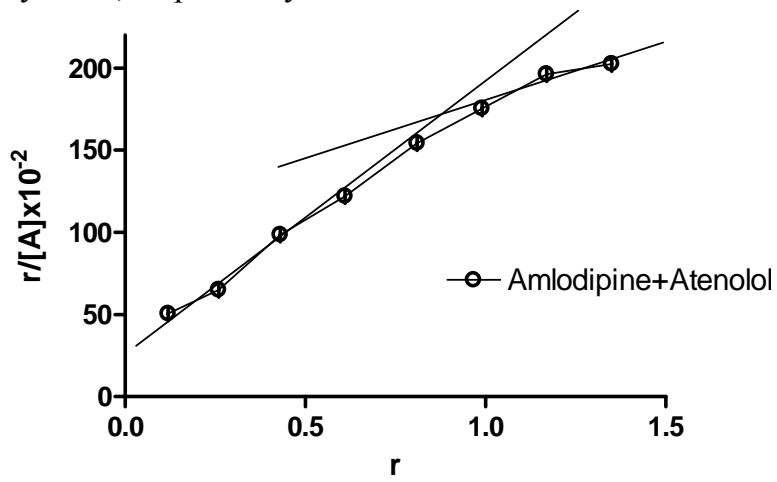

Figure 6. The Scatchard plot for protein binding capacity of amlodipine-atenolol system. The data are shown as mean \pm SEM

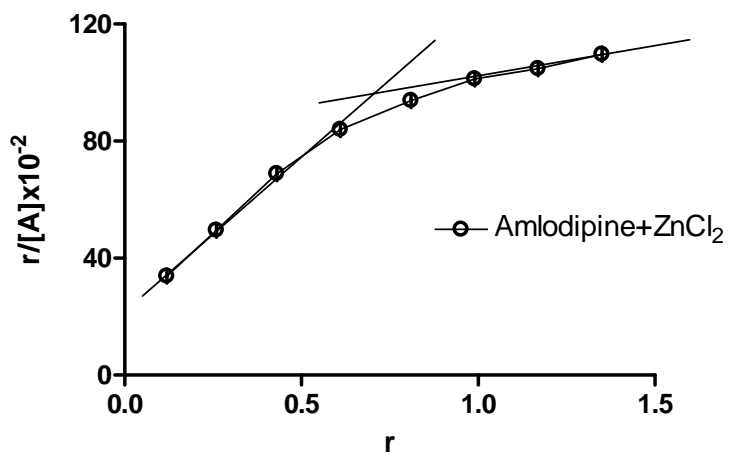

Figure 7. The Scatchard plot for protein binding capacity of amlodipine-zinc chloride system. The data are shown as mean \pm SEM 
The affinity constants $\left(\mathrm{K}_{2}\right)$ with them were 180 , 176 and 130 for amlodipine, amlodipine-atenolol and amlodipine-zinc chloride systems, respectively.

It is obvious, from these results, that the values of affinity constants for amlodipine is higher than that of its $1: 1$ complexes with atenolol and zinc chloride, i.e., the presence of atenolol and zinc chloride with amlodipine at physiological temperature and $\mathrm{pH}$ conditions cause a decrease in values of affinity constats or binding forces specially at lower concentrations as change in higher concentrations of plateau state is negligible. Due to this decrease in affinity of the drug to plasma protein binding, the volume of distribution of amlodipine may increase because affinity of a drug for protein binding is a limiting factor for the distibution of the drug. ${ }^{17}$ The values of affinity constants in class II binding sites revealed the same results, i.e., increase in volume of distribution of amlodipine. ${ }^{16}$ It is known that amlodipine undergoes heavy first pass metabolism and metabolized by liver. ${ }^{18}$ It is excreted through urine and its half life is $3.7 \pm 1.2$ hour. It was observed that the affinity for protein is lower for 1:1 complexes of amlodipine with atenolol and zinc chloride than that of amlodipine alone. As a result the intake of amlodipine as atenolol or zinc chloride complex or the concurrent therapy might increase both the hepatic and renal clearance of the drug as well as it may decrease the half life of the drug. ${ }^{19}$

\section{CONCLUSION}

Polypharmacy, that is, prescribing many drugs at a time is a common practice in case of patients undergoing a major operation, hospitalized patients, and also in jeriatric patients. Sometimes coadministration of more than two different classes of drugs may ensue effects that are neither safe nor effective but sometimes may be beneficial. It was observed that atenolol and zinc chloride lowerd the affinity of protein binding of amlodipine, and hence an increase in volume of distribution of amlodipine might be occured. Therefore, it can be inferred that care and monitoring should be practised during administration of amlodipine-atenolol and amlodipine-zinc chloride complexes or concurrent administration of amlodipine with atenolol and zinc chloride.

\section{ACKNOWLEDGEMENT}

The authors are grateful to Md. Rumman Hossain, an M. Pharm. research student for helping them to construct figures.

\section{REFERENCES}

1. Carlsted, B.C. and Stanazek, W.F. 1990, Angina pectoris, US Pharmacist, 10(12), 62-74

2. Martin, K. 1987. Cardiovascular disease, The pharmaceutical Journal, 199 (6792), 783-91

3. Baqui, A.H., Black, R.E., El Arifeen, S., Yunus, M., Chakraborty, J., Ahmed, S. and Vaughan, J.P. 2002, Effect of zinc suppliment started during diarrhea on morbidity and mortality in Bangladeshi children, British Medical Journal, 325(7372): 1059.

4. Chang, A.B., Torzillo, P.J., Boyce, N.C., White, A.V., Stewart, P.M., Wheaton, G.R. and Purdie, D.M. 2006. Zinc and vitamin A supplimentation in indigenous Australian children hospitalized with lower respiratory tract infection:a randomized control trial, Med J Aust. 184(3): 107-12.

5. Cadwallader, D.E. 1985. Biopharmaceutics and drug interactions, $3^{\text {rd }}$ edition, Raven press, New York, 107-143

6. Singlass, E. 1987. Protein binding of drugs, F. Hoffman La Roche \& co. Ltd., Basle, Switzerland, $2^{\text {nd }}$ edition, 17-32.

7. Perrin, D.D. and Boyd, D. 1974. Buffers for $\mathrm{pH}$ and metal ion control, Science papers back, New York, 44-64

8. Bates. 1964. Determination of $\mathrm{pH}$-Theory and practice, Wily, New York, 50-67.

9. British National Pharmacopoea, Volume-1, 2002, 117-119. the Stationary Office, London, UK.

10. Goldstein, A., Aronow, L. and Kalman, S.M. 1974, Principle of drug action-the basis of pharmacology, $2^{\text {nd }}$ edition, John wily and sons, New York, 47-52

11. Scatchard, G. 1949. The attractions of proteins for small molecules and ions, Ann NY Acad Sci, 660-673.

12. Amran, M.S., Zaman, M.R. and Hossain, M.A. 1999. Study of protein binding of diltiazem in presence of nifedipine and ketotifen fumarate, Rajshai Univ. Stud., Part-B, 27, 45-54.

13. Amran, M.S. and Hossain, M.A. 1998, Study of protein binding of diltiazem in presence of omeprazole and ranitidine, J. Bio Sci, 6, 115-121. 
14. Amran, M.S. and Hossain, M.A. 1999. Influence of ferrous sulphate on the protein binding of diltiazem in vitro, $J$. Bangladesh Acad Sci, 23(2), 125-131

15. Hossain, M.A. and Kamal, A.K.M. 1991. Protein binding of propranolol in the presence of theophylline, M.Pharm. Thesis, Department of Pharmacy, University of Dhaka, Dhaka, Bangladesh

16. Hossain, M.A. and Momen, A.Z.M.R. 1994. Protein binding of theophylline in presennce of cobalt, $J$ Bangladesh Chem Soc, 7(1), 93-103.

17. Tillement, J.P., Zini, R. and Vassent, G. 1974. Binding of certain acidic drugs to human albumin:theoretical and practical estimation of fundamental parameters, Euro J Clin Pharmacol. 7, 307-313.

18. Ascalone, V. 1987. Automated HPLC and column switching technique for online clean up and analysis of diltiazem in human plasma, J chromatograph. 423, 239-249.

19. Hansten, P.D. and Horn, J.R. 1989. Drug interactionsclinical significance of drug-drug interactions, $6^{\text {th }}$ edition, Philadelphia, 22-23. 